\title{
Effect of growth potential on the electrodeposition of CIS thin films
}

\author{
Vishakha N. Dhanwate $\cdot$ N. B. Chaure
}

Received: 1 November 2011 / Accepted: 22 January 2012/Published online: 14 February 2012

(C) The Author(s) 2012. This article is published with open access at Springerlink.com

\begin{abstract}
Thin films of copper indium diselenide (CIS) were prepared in aqueous bath by low-cost potentiostatic electrodeposition technique onto Fluorine doped tin oxide substrates. The deposition potential was optimized using cyclic voltammetry study in a ternary $\mathrm{Cu}-\mathrm{In}-\mathrm{Se}$ system. The films were characterized systematically with the aid of UV-Vis spectroscopy, IV measurements, X-ray diffraction, Scanning electron microscopy and Energy dispersive X-ray analysis. CIS films deposited for different growth potential shows the tetragonal structure with (112) preferential orientation. Annealing of the films at temperature $400^{\circ} \mathrm{C}$ not only improves the crystallinity of layers, but it also increases the grain size, which is suitable for the development of high efficiency solar cells.
\end{abstract}

Keywords I-III-VI semiconductor .

Copper indium diselenide - Electrochemical route ·

Three-electrode geometry

\section{Introduction}

Ternary chalcopyrite compounds $\mathrm{CuInX}_{2}(\mathrm{X}=\mathrm{S}, \mathrm{Se}, \mathrm{Te})$ are being considered as important semiconductor materials for thin film solar cell applications because it has a direct band gap $(1.08 \mathrm{eV})$ which can be tailored by the addition of gallium, high optical-absorption coefficient, good stability, largest efficiency, cost effective and chemically and environmentally stable (Arya et al. 1991; Chaure et al. 2005). Furthermore, these compounds can be easily

V. N. Dhanwate · N. B. Chaure ( $\square)$

Department of Physics, University of Pune, Pune 411007, India

e-mail: n.chaure@physics.unipune.ac.in deposited either $n$ - or $p$-type thin film form by controlling the elemental composition (Chaure et al. 2004; Chraibi et al. 2004). A CIGS solar cell achieved the highest efficiency of over $20 \%$ on laboratory scale with high-vacuum techniques (Repins et al. 2008) which indicate that CISbased solar cells are able to compete with Si-based solar cell. Various other deposition techniques apart from electrodeposition are used by researcher such as sputtering (Yamaguchi et al. 1992), co-sputtering of the elements (Arya et al. 1991), Rapid thermal processing (Karg et al. 1993), Pulse laser deposition (Wang et al. 2010), Spray pyrolysis (Bates et al. 1983) and Molecular beam epitaxy (Niki et al. 2002), etc.

In this paper we report the cathodic electrodeposition of $\mathrm{CuInSe}_{2}$ on a Fluorine doped tin oxide (FTO) substrates. Advantages of electrodeposition are low equipment cost, high deposition rate, negligible waste of chemicals and possibility to deposit over large area. Moreover, an isothermal process mainly controlled by concentration, temperature, $\mathrm{pH}$ of the electrolyte and applied potential. A Pourbaix diagram has been used as a guide to fix the preliminary electrodeposition conditions, $\mathrm{pH}$ and temperature of the electrolyte, concentration of ionic species etc. Thin film deposition under various conditions have been performed to understand the deposition mechanism and to optimize the deposition condition. The elemental composition and structural properties of the CIS thin films were studied by using Energy dispersive X-rays analysis and the $\mathrm{X}$-ray diffraction technique.

\section{Experimental details}

$\mathrm{CuInSe}_{2}$ (CIS) thin films were deposited on FTO-coated glass substrates of sheet resistance $15-20 \Omega / \mathrm{cm}^{2}$. A 
conventional three-electrode electrochemical cell was employed for the deposition of thin films consisting FTO as a working electrode, graphite as a counter electrode and $\mathrm{Ag} / \mathrm{AgCl}$ as a reference electrode (Pandey et al. 1996). The ionic source for $\mathrm{Cu}$, In and $\mathrm{Se}$ was $\mathrm{CuSO}_{4}$ $\cdot 5 \mathrm{H}_{2} \mathrm{O}, \mathrm{In}_{2}\left(\mathrm{SO}_{4}\right)_{3} \cdot 5 \mathrm{H}_{2} \mathrm{O}$ and $\mathrm{H}_{2} \mathrm{SeO}_{3}$. The details are reported elsewhere (Chaure et al. 2004). Lithium sulfate was used as a supporting electrolyte, to bring deposition potential of all species closer for a better co-deposition of $\mathrm{Cu}$, In and Se. Triethanolamine (TEA) was used as a complexing agent which forms complex with copper that reduces the rate of copper reduction and shifts copper deposition potential towards cathodic direction. Triethanolamine also improves the adhesion of film to the substrate. Similar results are reported by Whang et al. (2009) and $\mathrm{Yu}$ et al. (2010). Indeed, we found that the films deposited in presence of TEA were highly uniform, very well adhesive to the substrate and free of loosely bound particles on the surface of sample. The above precursors were dissolved in double-distilled water with appropriate molar concentration. The $\mathrm{pH}$ of bath was adjusted $\sim 2$ using $\mathrm{H}_{2} \mathrm{SO}_{4}$ or $\mathrm{NaOH}$. Cyclic voltammetry (CV) and potentiostatic deposition of CIS layers were carried out using $\mu 3$ AUT 70762 AUTOLAB potentiostat of working temperature $\sim 40^{\circ} \mathrm{C}$ without stirring. The information observed in $\mathrm{CV}$ was used to optimize the film deposition potential. The films were deposited at various growth potentials ranging from -0.6 to $-0.9 \mathrm{~V}$ with respect to $\mathrm{Ag} / \mathrm{AgCl}$. The layers were annealed $\sim 400^{\circ} \mathrm{C}$ for $10 \mathrm{~min}$ to improve homogeneity and crystalline nature. Subsequently, the films were characterized using range of characterization techniques.

\section{Results and discussion}

Cyclic voltammetry was recorded to understand the codeposition procedure of $\mathrm{Cu}$, In and Se. Figure 1 shows the $\mathrm{CV}$ recorded for CIS bath on FTO working electrode. The features related to the deposition of elemental, binary and ternary phases of CIS were observed. Initially, at lower cathodic potential up to $-0.4 \mathrm{~V}$, the features noticed were related to the reduction of $\mathrm{Cu}$ and $\mathrm{Se}$ by charge-transfer reaction;

$$
\begin{aligned}
& \mathrm{Cu}^{2+}+2 \mathrm{e}^{-} \rightarrow \mathrm{Cu}(\mathrm{s}) ; E_{0}=0.34 \mathrm{~V}(\mathrm{NHE}) \\
& \begin{aligned}
\mathrm{HSeO}_{2}^{+}+4 \mathrm{e}^{-}+3 \mathrm{H}^{+} & \rightarrow \mathrm{Se}(\mathrm{s})+3 \mathrm{H}_{2} \mathrm{O} ; E_{0} \\
& =0.74 \mathrm{~V}(\mathrm{NHE})
\end{aligned}
\end{aligned}
$$

The deposition of indium was observed beyond the potential $-0.6 \mathrm{~V}$ with respect to $\mathrm{Ag} / \mathrm{AgCl}$ reference electrode, by following charge-transfer reaction;

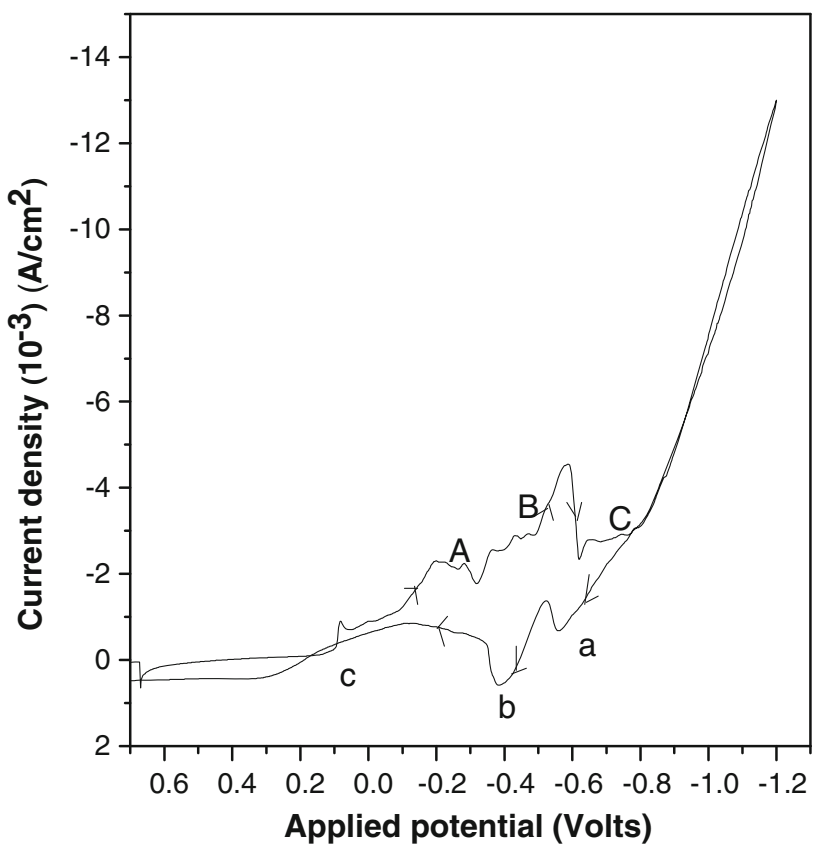

Fig. 1 Cyclic voltammogram recorded on FTO in the presence of $\mathrm{Cu}$, In and $\mathrm{Se}$ in electrolytic bath

$\mathrm{In}^{3+}+3 \mathrm{e}^{-} \rightarrow \operatorname{In}(\mathrm{s}) ; E_{0}=-0.34 \mathrm{~V}(\mathrm{NHE})$

A plateau observed in between -0.7 and $-0.9 \mathrm{~V}$ favors the deposition of CIS alloys. Sharp linear rise in cathodic current observed beyond $-0.9 \mathrm{~V}$ could be due to the metallic deposition of indium along with hydrogen evolution. CIS can be formed by the chemical reaction:

$$
\begin{aligned}
& \mathrm{Cu}^{2+}+\mathrm{In}^{3+}+2 \mathrm{SeO}_{2}^{-}+12 \mathrm{H}^{+}+13 \mathrm{e}^{-} \\
& \quad \rightarrow \mathrm{CuInSe}_{2}+6 \mathrm{H}_{2} \mathrm{O}
\end{aligned}
$$

During anodic curve, the dissolution (stripping) peaks for In, $\mathrm{Cu}$ and Se were observed and marked as $a, b$ and $c$, respectively.

Theoretical thickness of the films deposited at various potentials was calculated using Faraday's law:

$T=\frac{1}{n F A}\left[\frac{i t M}{\rho}\right]$

where ' $n$ ' is the number of electron transferred, ' $F$ ' is the Faraday's constant, ' $A$ ' is the area of electrode, ' $i$ ' is the current, ' $t$ ' is the deposition time, ' $M$ ' is the formula weight, and ' $\rho$ ' is the density of intrinsic CIS (Friedfeld et al. 1999).

Thickness measured for the samples deposited at potential -0.8 and $-0.9 \mathrm{~V}$ was 590 and $650 \mathrm{~nm}$ $( \pm 20 \mathrm{~nm})$, respectively. Note that the deposition time was kept constant (10 $\mathrm{min}$ ) for the deposition of above samples.

Structural characterization was carried out with the help of X-ray diffraction (D8 Bruker). The X-ray diffractogram of the CIS thin film deposited at different potential is 
shown in Fig. 2. The presence of sharp peaks in the X-ray diffractogram shows that CIS is polycrystalline in nature. The CIS is found to exhibit chalcopyrite tetragonal structure with a preferred orientation along certain crystallographic planes which have been identified as (112), (204/ 220), (116/312). The secondary binary phases $\mathrm{Cu}_{x} \mathrm{Se}$ and $\mathrm{In}_{x} \mathrm{Se}$ were observed for the film deposited for $-0.6,-0.7$ and $-0.9 \mathrm{~V}$, whereas stoichiometric film along with high intensity CIS peaks were observed for the layer deposited at $-0.8 \mathrm{~V}$. Note that no secondary phases were observed for film deposited at $-0.8 \mathrm{~V}$. The substrates (FTO) peaks were also observed in XRD spectra which are marked as solid circles. Lattice parameter for tetragonal structure can be obtained by the formula,

$\frac{1}{d^{2}}=\left[\frac{h^{2}+l^{2}}{a^{2}}+\frac{k^{2}}{c^{2}}\right]$.

The lattice parameter was calculated to be 5.783 and $11.73 \AA$ which gives tetragonal distortion i.e., $c / a$ ratio is approximately equal to 2 .

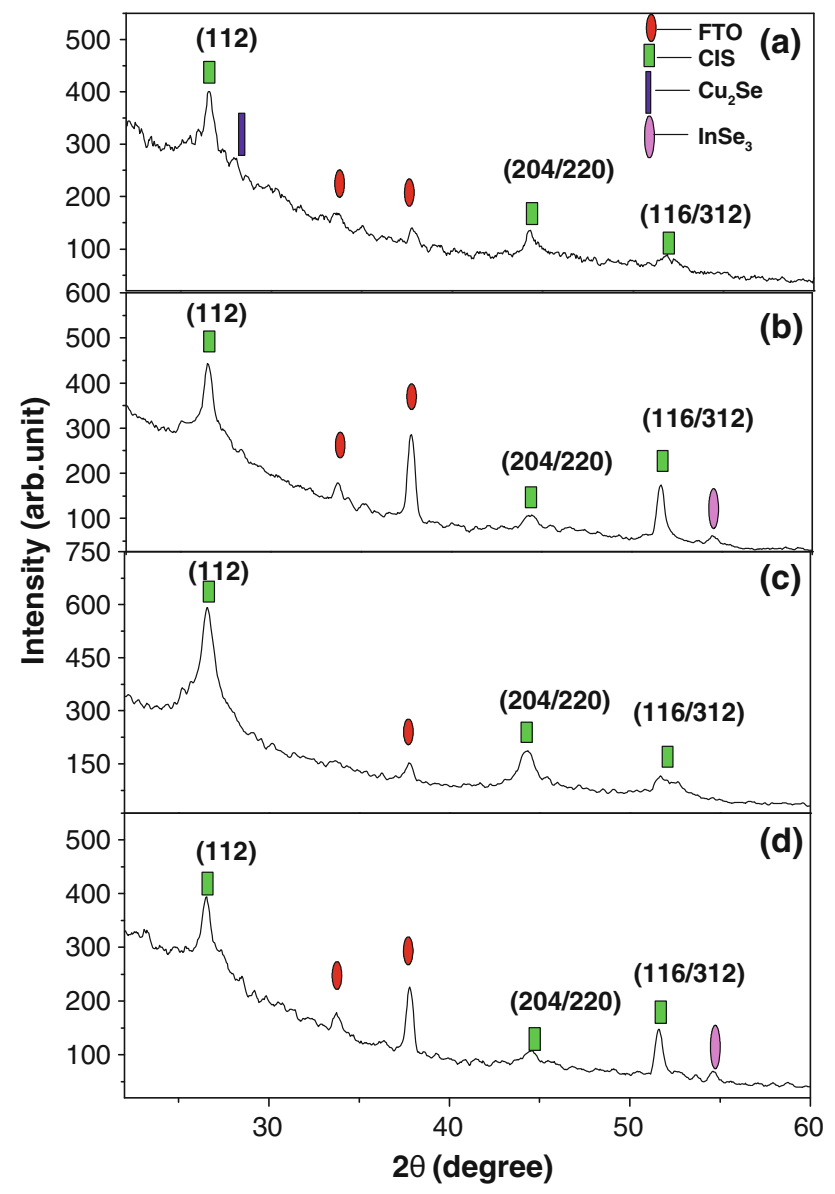

Fig. 2 XRD spectra of as-deposited film at potentials. a $-0.6 \mathrm{~V}$, $\mathbf{b}-0.7 \mathrm{~V}, \mathbf{c}-0.8 \mathrm{~V}$ and $\mathbf{d}-0.9 \mathrm{~V}$ with respect to $\mathrm{Ag} / \mathrm{AgCl}$ reference electrode
Post deposition heat treatment on CIS films was carried out in the furnace at $400^{\circ} \mathrm{C}\left( \pm 5^{\circ} \mathrm{C}\right)$ for $10 \mathrm{~min}$. After heat treatment the peak intensity improves which indicates the improvement in crystallinity of CIS thin films (Kemell Marianna et al. 2000). The X-ray patterns obtained for as-deposited and annealed CIS thin film are shown in (Fig. 3).

The grain size of as-deposited and annealed sample was calculated using the Scherrer equation,

$t=\frac{0.9 \lambda}{\beta \cos \theta}$

where $\lambda$ is the wavelength, $\beta$ is the FWHM and $\theta$ is the diffraction angle (Cullity and Stock 1978). Grain size of the as-deposited and annealed sample of CIS was calculated approximately 13 and $24 \mathrm{~nm}$, respectively (Panchal et al. 2009).

Compositional and morphological analysis was carried out using SEM and EDAX (JEOL JSM-6360A). Figure $4 \mathrm{a}-\mathrm{d}$ shows the SEM images of as-deposited CIS, deposited at potential $-0.6,-0.7,-0.8$ and $-0.9 \mathrm{~V}$, respectively. All the films show uniform and compact deposition. CIS layer deposited at $-0.8 \mathrm{~V}$ was compact, spherical and uniform, whereas the mixed morphology consisting uniform grains along with irregular shaped clusters were observed for other samples. After annealing CIS films become compact and power free with grayish metallic finishing. Heat treated sample (Fig. 5) can be clearly seen the grain enhancement along with noticeable improvement in crystallinity.

The elemental composition was detected by EDAX at accelerated voltage $20 \mathrm{kV}$ and probe current $1 \mathrm{nA}$. Table 1 shows the chemical composition of as deposited CIS films at potentials $-0.6,-0.7,-0.8$ and $-0.9 \mathrm{~V}$.

CIS layer deposited at $-0.8 \mathrm{~V}$ was nearly stoichiometric 24:25:51 for Cu:In:Se. The growth potential plays an important role to control the stoichiometry of layer. The $\mathrm{Cu}$-rich and In-rich layers are $p$-type and $n$-type, respectively (Chaure et al. 2005). The optical band gap was estimated from Fig. 6 by plotting the graph $(\alpha h v)^{2}$ as a function of $(h v)$. The electronic transition between the valance and conduction band in case of CIS was direct transition. The transition of electron can be allowed as permitted by the transition probability or forbidden where no such probability exists. The transition probability is given by the Eq. 8. The absorption coefficient was calculated of the order of $10^{4}$ per $\mathrm{cm}$. Similar value is reported by Friedfeld et al. (1999).

$(\alpha h v)^{2}=\alpha_{0}\left(h v-E_{\mathrm{g}}\right)$

where $E_{\mathrm{g}}$ denotes the band gap, $h v$ the energy of the incident photon and $\alpha_{0}$ is a constant. Value of $E_{\mathrm{g}}$ was obtained by extrapolating the linear portion of the graph to intercept 
Fig. 3 XRD spectra of CIS deposited film at potential $-0.8 \mathrm{~V}$; a as-deposited and b annealed at $400^{\circ} \mathrm{C}$ for $10 \mathrm{~min}$

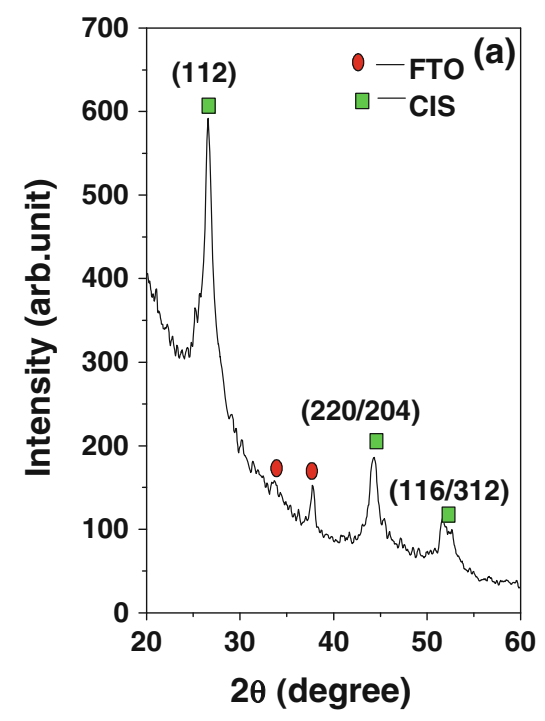

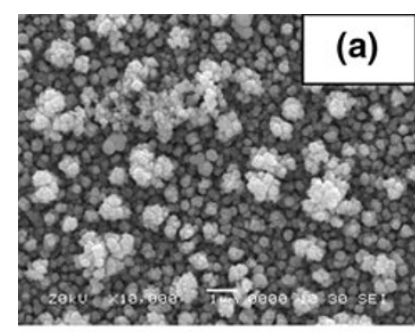
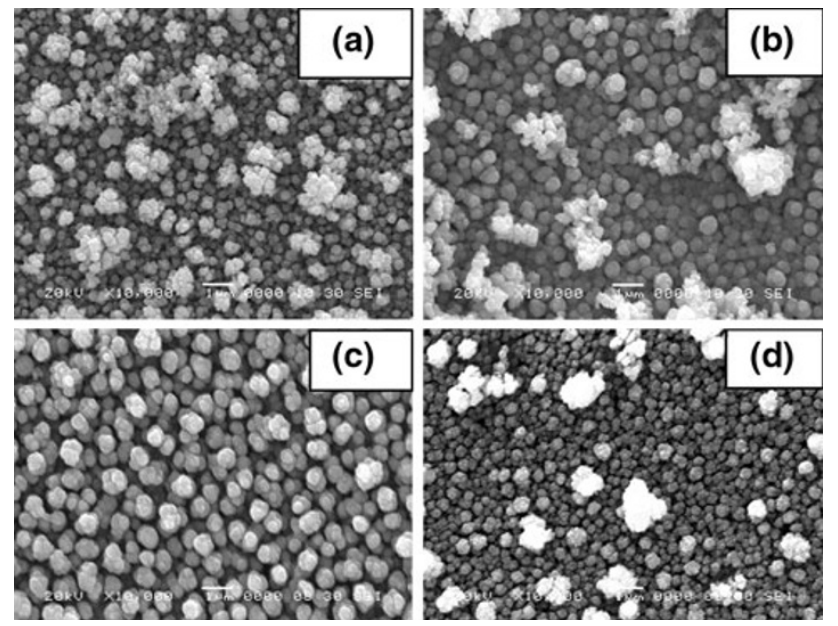

Fig. 4 SEM images of as-deposited films at potentials. a $-0.6 \mathrm{~V}$, $\mathbf{b}-0.7 \mathrm{~V}, \mathbf{c}-0.8 \mathrm{~V}$ and $\mathbf{d}-0.9 \mathrm{~V}$ with respect to $\mathrm{Ag} / \mathrm{AgCl}$ reference electrode

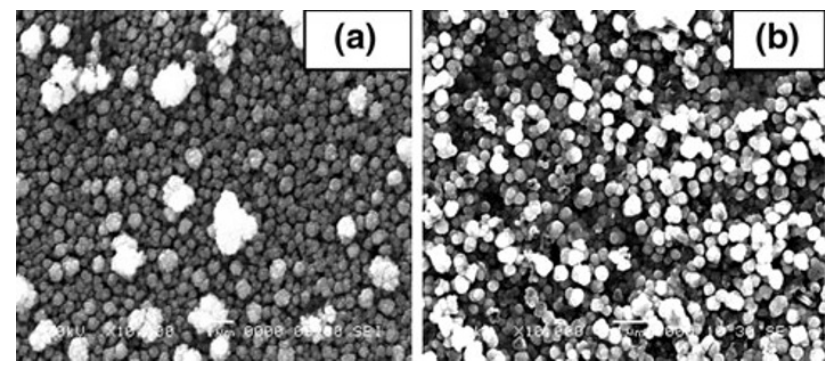

Fig. 5 SEM images of CIS deposited film at potential $-0.8 \mathrm{~V}$; a as-deposited and $\mathbf{b}$ annealed at $400^{\circ} \mathrm{C}$ for $10 \mathrm{~min}$

the photon energy axis. After annealing, the band gap comes to very closer to that of ideal value which is $1.04 \mathrm{eV}$.
Table 1 Atomic percentage composition of CIS thin films by EDAX

\begin{tabular}{llrl}
\hline $\begin{array}{l}\text { Cathodic deposition potential } \\
\text { with respect to } \mathrm{Ag} / \mathrm{AgCl}(\mathrm{V})\end{array}$ & \multicolumn{3}{l}{ Atomic compositions (\%) } \\
\cline { 2 - 4 } & $\mathrm{Cu}$ & $\mathrm{In}$ & $\mathrm{Se}$ \\
\hline-0.6 & 26.34 & 3.50 & 70.16 \\
-0.7 & 25.69 & 14.49 & 59.82 \\
-0.8 & 23.68 & 24.93 & 51.39 \\
-0.9 & 18.36 & 25.69 & 55.95 \\
\hline
\end{tabular}

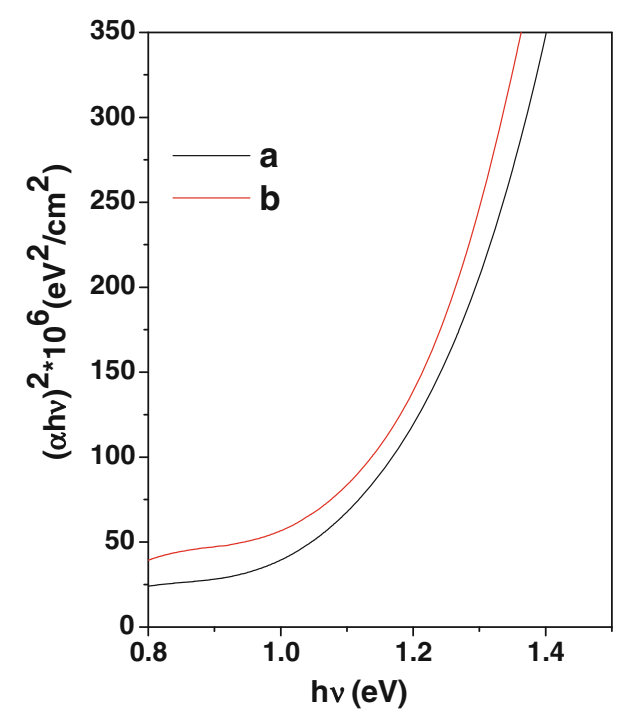

Fig. 6 Plot of $(\alpha h v)^{2}$ versus (hv) of CIS deposited film at potential $-0.8 \mathrm{~V} ; a$ as-deposited and $b$ annealed at $400^{\circ} \mathrm{C}$ for $10 \mathrm{~min}$

\section{Electrical measurements}

The electrical studies were performed on FTO/CIS/Al structure (Fig. 7). 


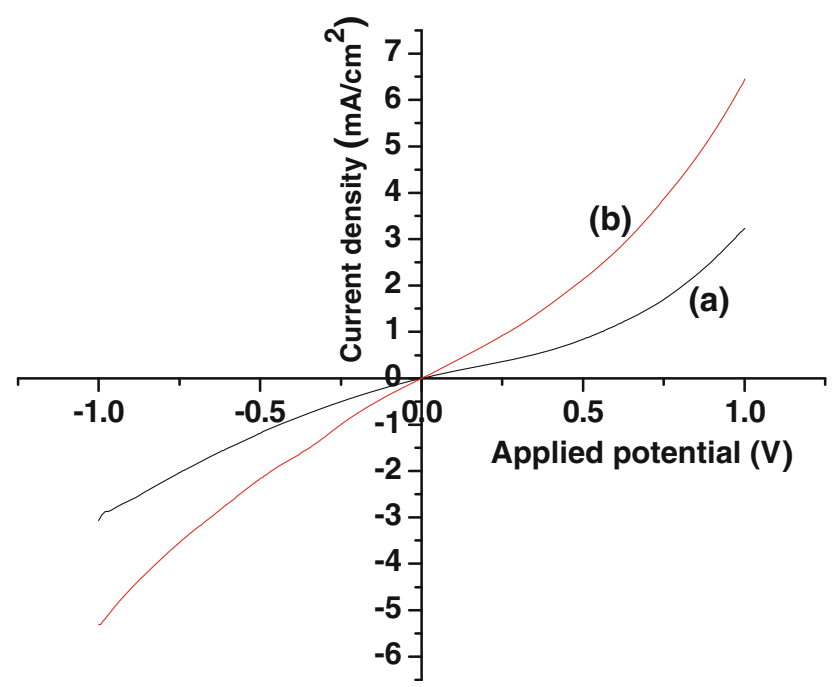

Fig. 7 I-V characteristics of CIS films deposited at potential $-0.8 \mathrm{~V}$; $a$ as-deposited and $b$ annealed at $400^{\circ} \mathrm{C}$ for $10 \mathrm{~min}$

An electrical measurement shows Schottky behavior of diode. IV curve clearly shows that the improvement in conductivity after heat treatment. The improvement in current indicates the decrease in grain boundaries and defects.

\section{Conclusion}

CIS films were potentiostatically electrodeposited from aqueous bath. A plateau observed between -0.7 and $-0.9 \mathrm{~V}$ was found to be suitable for the deposition of CIS films. CIS films deposited at reported potentials were polycrystalline with tetragonal chalcopyrite structure. The optical band gap was estimated to be $1.04 \mathrm{eV}$. SEM study showed that the CIS films are uniform, densely compact, and free from pores. From EDAX, it has been observed that the growth potential plays an important role to control the stoichiometry of film. Stoichiometry of the thin film deposited at $-0.8 \mathrm{~V}$ is very close to the desired composition of film. The current density has been increased for heat treated sample could be due to change in conductivity of material as well as the defects present in as-deposited sample may be reduced. Further study on CIS is under progress and the development of superstrate and substrate solar cell devices will be the topic of future work.

Acknowledgments The authors gratefully acknowledge the financial support received from Board of College and University Development (BCUD), University of Pune.

Open Access This article is distributed under the terms of the Creative Commons Attribution License which permits any use, distribution, and reproduction in any medium, provided the original author(s) and the source are credited.

\section{References}

Arya RR, Lommasson T, Fieselmannm B, Russell L, Carr L, Catalano A (1991) CIS solar cells by elemental sputtering. Rec IEEE Photovolt Special Conf 2:903-906

Bates CW, Uekita M, Nelson KF, Abernathy CR, Mooney JB (1983) Effect of $\mathrm{pH}$ on the production of chalcopyrite $\mathrm{CuInSe} 2$ prepared by spray pyrolysis. Appl Phys Lett 43:851-852

Chaure NB, Young J, Samantilleke AP, Dharmadasa IM (2004) Electrodeposition of $\mathrm{p}-\mathrm{i}-\mathrm{n}$ type $\mathrm{CuInSe}_{2}$ multilayers for photovoltaic. Appl Solar Energy Mater Solar Cells 81:125-133

Chaure NB, Samantilleke AP, Burton RP, Young J, Dharmadasa IM (2005) Electrodeposition of $\mathrm{p}+, \mathrm{p}, \mathrm{i}, \mathrm{n}$ and $\mathrm{n}+$-type copper indium gallium diselenide for development of multilayer thin film solar cells. Thin Solid Films Film 472:212-216

Chraibi F, Fahoume M, Ennaui A, Delplancke JL (2004) One step electrodeposition of CuInSe2 thin Films. M J Condensed Matter $5: 1$

Cullity BD, Stock SR (1978) Elements of X-ray diffraction. PrentieHall Inc, New Jersey

Friedfeld R, Raffaelle RP, Mantovani JG (1999) Electrodeposition of $\mathrm{CuIn} x \mathrm{Ga} 1 \sim x \mathrm{Se} 2$ thin films. Sol Energy Mater Sol Cells $58: 375-385$

Karg VP, Harms H, Rimmasch J, Riedl W, Kotschy J, Holz J, Treichler R, Eibl O, Mitwalskotschy A, Holz J, Kiendl A (1993) Novel rapid thermal processing for CIS thin film solar cell. Rec IEEE Photovol Special Conf 23:441-446

Marianna K, Ritala M, Leskela M (2000) Effects of post-deposition treatments on the photoactivity of CuInSe2 thin films deposited by the induced co-deposition mechanism. J Mater Chem 11:668-672

Niki S, Yamada A, Hunger R, Fons PJ, Iwata K, Matsubara K, Nishio A, Nakanishi H (2002) Molecular beam epitaxial growth and characterization of $\mathrm{CuInSe} 2$ and $\mathrm{CuGaSe} 2$ for device applications. J Cryst Growth 237-239:1993-1999

Panchal CJ, Rehani B (2009) Structural, optical, and electrical properties of flash-evaporated copper indium diselenide thin films. J Mater Sci 44:316-322

Pandey RK, Sahu SN, Chandra S (1996) Handbook of semiconductor electrodeposition. Marcel Dekker Inc., New York

Repins I, Contreras MA, Egaas B, DeHart C, Scharf J, Perkins CL, To B, Noufi R (2008) 19 9\%-efficient $\mathrm{ZnO} / \mathrm{CdS} / \mathrm{CuInGaSe} 2$ solar cell with $812 \%$ fill factor. Prog Photovolt Res Appl 16:235-239

Wang XL, Wang GJ, Tian BL, Wan SM, Du ZL (2010) CuInSe2 thin films obtained by pulse-plating electrodeposition technique with novel pulse wave. Chin Sci Bull 55:1854-1858

Whang T-J, Hsieh M-T, Kao Y-C, Lee S-J (2009) A study of electrodeposition of $\mathrm{CuInSe} 2$ thin films with triethanolamine as the complexing agent. Appl Surf Sci 255:4600-4605

Yamaguchi T, Matsufusa J, Yoshida A (1992) Structural properties of CuInxGa1-xSe2 thin films prepared by rf sputtering. J Appl Phys 72:5657

Yu R, Ren T, Li C (2010) Effect of triethanolamine and sodium dodecyl sulfate on the formation of CuInSe2 thin films by electrodeposition. Thin Solid Films 518:5515-5519 